\title{
Instalações Elétricas de Baixa Tensão Dimensionamento de Condutas
}

\section{Enquadramento}

O dimensionamento das condutas deverá ter em consideração o número de condutores isolados ou cabos que poderão ser colocados nessa mesma conduta, tendo por base as suas características, o modo de instalação das canalizações e o diâmetro útil (interior) da própria conduta.

Nas Regras Técnicas de Instalações Eléctricas de Baixa Tensão, com exceção, das instalações coletivas e entradas, não é definido um valor máximo de ocupação da secção reta interior das condutas pelos condutores isolados e cabos, sendo o único requisito a garantir, que as condutas permitam o fácil enfiamento e desenfiamento dos condutores isolados e cabos. No entanto, as mesmas regras recomendam uma ocupação da conduta não superior a um terço da sua secção reta interna, de forma a garantir, nomeadamente, o fácil enfiamento (e desenfiamento) dos condutores isolados e dos cabos.

\section{Condutas de Instalações Coletivas e Entradas}

Para estas condutas, as Regras Técnicas de Instalações Eléctricas de Baixa Tensão, definem o valor máximo de ocupação da secção reta interior das condutas pelos condutores isolados e cabos, conforme se apresenta seguidamente.

\subsection{Primeiro Estabelecimento}

No que se refere ao dimensionamento de condutas para as colunas de instalações coletivas e entradas, tendo em consideração o disposto nas Regras Técnicas de Instalações Eléctricas de Baixa Tensão, no caso de nas colunas serem utilizados condutores isolados do tipo H07V e tubos do tipo VD, para as situações de primeiro estabelecimento da instalação, dever-se-à observar os diâmetros indicados na tabela 1.
Tabela 1 - Diâmetro nominal dos tubos do tipo VD, em função da secção e do número de condutores da coluna (primeiro estabelecimento)

\begin{tabular}{|c|c|c|c|c|c|}
\hline \multirow{3}{*}{$\begin{array}{c}\text { Secção } \\
\text { nominal } \\
\text { condutores } \\
\left(\mathrm{mm}^{2}\right) \\
\end{array}$} & \multicolumn{5}{|c|}{$\begin{array}{l}\text { Diâmetro nominal dos tubos } \\
\qquad(\mathrm{mm})\end{array}$} \\
\hline & \multicolumn{5}{|c|}{ Número de condutores } \\
\hline & 1 & 2 & 3 & 4 & 5 \\
\hline 10 & 32 & 32 & 32 & 40 & 40 \\
\hline 16 & 32 & 32 & 40 & 40 & 50 \\
\hline 25 & 32 & 40 & 50 & 50 & 63 \\
\hline 35 & 32 & 50 & 63 & 63 & 63 \\
\hline 50 & 40 & 50 & 63 & 75 & 75 \\
\hline 70 & 40 & 63 & 75 & 75 & 90 \\
\hline 95 & 50 & 63 & 90 & 90 & 90 \\
\hline 120 & 50 & 75 & 90 & 110 & 110 \\
\hline 150 & 63 & 90 & 110 & 110 & 110 \\
\hline 185 & 63 & 90 & 110 & 110 & - \\
\hline 240 & 75 & 110 & - & - & - \\
\hline 300 & 75 & 110 & - & - & - \\
\hline 400 & 90 & - & - & - & - \\
\hline 500 & 110 & - & - & - & - \\
\hline \multicolumn{6}{|c|}{$\begin{array}{l}\text { Para condutores de secção nominal superior a } 16 \mathrm{~mm}^{2} \text {, os valores } \\
\text { correspondentes a quatro e a cinco condutores consideram que, } \\
\text { respetivamente, } 1 \text { ou } 2 \text { condutores são de secção reduzida (condutor } \\
\text { neutro - N e condutor de protecção- PE). }\end{array}$} \\
\hline
\end{tabular}

No caso de, nas colunas, serem utilizados cabos ou outros condutores isolados e condutas, que não os do tipo condutores isolados do tipo H07V e tubos do tipo VD, o diâmetro ou as dimensões da secção reta das condutas devem ser determinados de modo que a soma das secções correspondentes ao diâmetro exterior médio máximo dos condutores isolados ou cabos não exceda $20 \%$ da secção reta interior da conduta. 


\subsection{Após o Primeiro Estabelecimento}

Posteriormente à execução e à entrada em funcionamento da instalação, caso se verifique a necessidade de um aumento de potência e isso implique a substiuição dos condutores da coluna, com vista a minimizar os custos inerentes a essa alteração, é admissível, nessa situação uma ocupação maior das condutas.

A tabela 2 mostra quais as ocupações máximas para intervenções após o primeiro estabelecimento das canalizações elétricas, no caso de na remodelação da(s) coluna(s) ser(em) utilizado(s) condutores isolados do tipo HO7V e de tubos do tipo VD.

Tabela 2 - Diâmetro nominal dos tubos do tipo VD, em função da secção e do número de condutores da coluna

(em caso de aumento de potência)

\begin{tabular}{|c|c|c|c|c|c|}
\hline \multirow{3}{*}{$\begin{array}{c}\text { Secção nominal } \\
\text { dos condutores } \\
\left(\mathrm{mm}^{2}\right)\end{array}$} & \multicolumn{5}{|c|}{$\begin{array}{l}\text { Diâmetro nominal dos tubos } \\
\qquad(\mathrm{mm})\end{array}$} \\
\hline & \multicolumn{5}{|c|}{ Número de condutores } \\
\hline & 1 & 2 & 3 & 4 & 5 \\
\hline 10 & 16 & 20 & 25 & 32 & 32 \\
\hline 16 & 16 & 25 & 32 & 32 & 32 \\
\hline 25 & 20 & 32 & 32 & 40 & 40 \\
\hline 35 & 25 & 32 & 40 & 40 & 50 \\
\hline 50 & 25 & 40 & 50 & 50 & 50 \\
\hline 70 & 32 & 40 & 50 & 63 & 63 \\
\hline 95 & 32 & 50 & 63 & 63 & 75 \\
\hline 120 & 40 & 50 & 63 & 75 & 75 \\
\hline 150 & 40 & 63 & 75 & 75 & 90 \\
\hline 185 & 50 & 63 & 75 & 90 & 90 \\
\hline 240 & 50 & 75 & 90 & 90 & 110 \\
\hline 300 & 63 & 75 & 110 & 110 & 110 \\
\hline 400 & 63 & 90 & 110 & 110 & - \\
\hline 500 & 75 & 110 & - & - & - \\
\hline \multicolumn{6}{|c|}{$\begin{array}{l}\text { Para condutores de seç̧ão nominal superior a } 16 \mathrm{~mm}^{2} \text {, os valores } \\
\text { correspondentes a quatro e a cinco condutores consideram que, } \\
\text { respetivamente, } 1 \text { ou } 2 \text { condutores são de secção reduzida } \\
\text { (condutor neutro - } \mathrm{N} \text { e condutor de proteç̧ão-PE). }\end{array}$} \\
\hline
\end{tabular}

No caso de na remodelação, das colunas, serem utilizados cabos ou outros condutores isolados e condutas, que não os do tipo condutores isolados do tipo H07V e de tubos do tipo VD, o diâmetro ou as dimensões da secção reta das condutas devem ser determinados de modo que a soma das secções correspondentes ao diâmetro exterior médio máximo dos condutores isolados ou cabos não exceda $40 \%$ da secção reta interior da conduta.

\section{Outras Condutas}

Para o dimensionamento de outras condutas, que não as de instalações coletivas e entradas são, seguidamente, sugeridas algumas regras gerais de dimensionamento, que eram as observadas no anterior regulamento.

\subsection{Condutas à Vista}

No dimensionamento de condutas à vista, a soma das áreas transversais da totalidade dos condutores isolados ou cabos colocados na conduta não deverá exceder $40 \%$ da secção transversal da conduta.

\subsection{Condutas Embebidas}

No dimensionamento de condutas embebidas, a soma das áreas transversais da totalidade dos condutores isolados ou cabos colocados na conduta não deverá exceder 33\% da secção transversal da conduta.

\subsection{Condutas Circulares (Tubos)}

Para o caso particular de condutas circulares (tubos), as tabelas 3 e 4, indicam, para condutores do tipo H07V e condutas circulares (tubos) do tipo VD, os diâmetros comerciais em função do número de condutores colocados nas mesmas, para canalizações embebidas e canalizações à vista, respetivamente. 
Para canalizações realizadas com condutas circulares (tubos), ou condutores, que não os acima referidos, será necessário atender às regras de ocupação, atrás referidas, para dimensionamento dessas condutas.

Tabela 3 - Diâmetro das condutas circulares (tubos) em canalizações embebidas

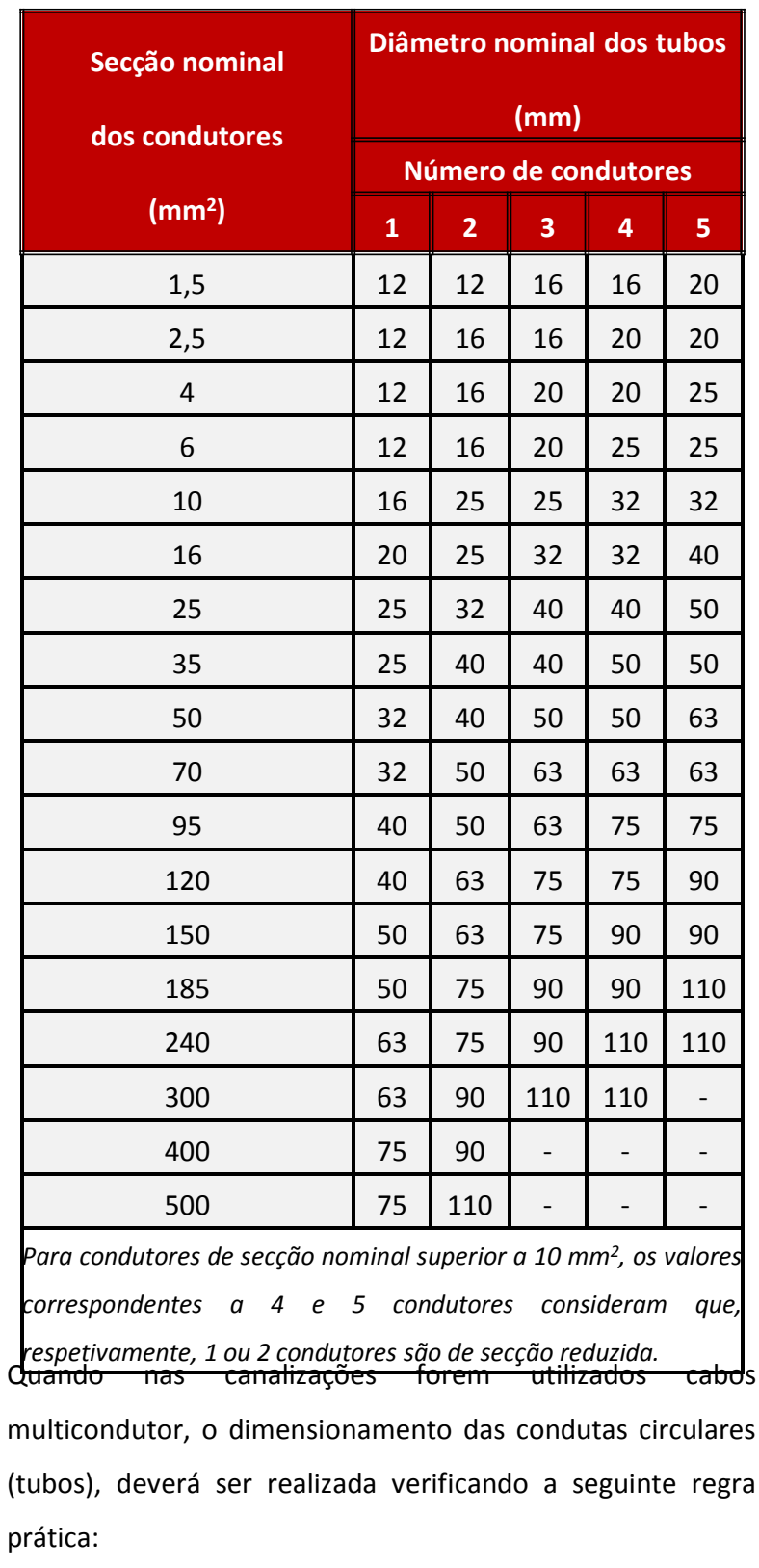

\section{- Canalizações à Vista}

$$
D_{\text {Tubo }}=1,742 \times D_{\text {cabo }}
$$

Tabela 4 - Diâmetro das condutas circulares (tubos) em canalizações à vista

\begin{tabular}{|c|c|c|c|c|c|}
\hline \multirow{3}{*}{$\begin{array}{l}\text { Secção nominal } \\
\text { dos condutores } \\
\left(\mathrm{mm}^{2}\right)\end{array}$} & \multirow{2}{*}{\multicolumn{5}{|c|}{$\begin{array}{l}\text { Diâmetro nominal dos tubos } \\
\qquad(\mathrm{mm}) \\
\text { Número de condutores }\end{array}$}} \\
\hline & & & & & \\
\hline & 1 & 2 & 3 & 4 & 5 \\
\hline 1,5 & 12 & 12 & 16 & 16 & 20 \\
\hline 2,5 & 12 & 16 & 16 & 20 & 20 \\
\hline 4 & 12 & 16 & 20 & 20 & 25 \\
\hline 6 & 12 & 16 & 20 & 25 & 25 \\
\hline 10 & 16 & 25 & 25 & 32 & 32 \\
\hline 16 & 20 & 25 & 32 & 32 & 40 \\
\hline 25 & 25 & 32 & 40 & 40 & 50 \\
\hline 35 & 25 & 40 & 40 & 50 & 50 \\
\hline 50 & 32 & 40 & 50 & 50 & 63 \\
\hline 70 & 32 & 50 & 63 & 63 & 63 \\
\hline 95 & 40 & 50 & 63 & 75 & 75 \\
\hline 120 & 40 & 63 & 75 & 75 & 90 \\
\hline 150 & 50 & 63 & 75 & 90 & 90 \\
\hline 185 & 50 & 75 & 90 & 90 & 110 \\
\hline 240 & 63 & 75 & 90 & 110 & 110 \\
\hline 300 & 63 & 90 & 110 & 110 & - \\
\hline 400 & 75 & 110 & - & - & - \\
\hline 500 & 75 & 110 & - & - & - \\
\hline \multicolumn{6}{|c|}{ 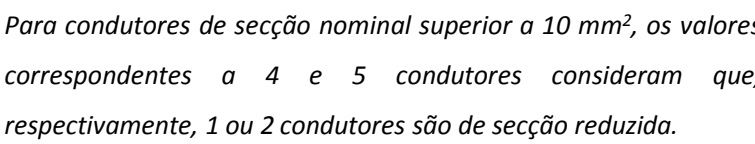 } \\
\hline
\end{tabular}

- Canalizações Embebidas

$D_{\text {Tubo }}=1,585 \times D_{\text {Cabo }}$ 